\title{
CONJUGATION OF SULFOBROMOPHTHALEIN SODIUM WITH GLUTATHIONE IN THIOETHER LINKAGE BY THE RAT *
}

\author{
BY BLRTON COMBES† $\Lambda_{N D}$ GENEVA SUE STAKELUM \\ (From the Department of Intcrnal Medicine, The Unizersity of Tcxas Southwestern Medical \\ School, Dallas, Texas)
}

(Submitted for publication February 29, 1960; accepted April 7, 1960)

Most of the sulfobromophthalein sodium (BSP) appearing in the bile of man, rat, dog, sheep and cat differs chromatographically from the free BSP originally administered (1-4). The altered BSP compounds in man, rat and dog appear to be amino acid conjugates (2-4). Thus, after hydrolysis of the major BSP compounds with $6 \mathrm{~N} \mathrm{HCl}$, several amino acids have been detected by filter paper chromatography. Glycine, glutamic acid and alanine were identified in man $(2,3)$, glycine and glutamic acid in the rat (2) and glycine in the dog (3).

Recently, in a preliminary report, Javitt. Wheeler, Baker and Ramos (5) suggested that $\mathrm{BSP}$ appears in bile of the dog as a conjugate of glutathione. These authors found glycine, glutamic acid and evidence of free sulfhydryl groups, as manifested by a positive sodium azide-iodine reaction, after alkaline hydrolysis of the major BSP conjugates. Occasionally, cysteine was detectable. BSP conjugates formed in vitro by admixture of BSP and glutathione were identical electrophoretically and chromatographically with conjugates found in bile. Cysteine has also been identified in human BSP conjugates by Grodsky, Carbone and Fanska (4). Cysteine was difficult to detect after hydrolysis with concentrated $\mathrm{HCl}$, but was more clearly demonstrated when the BSP compounds were hydrolyzed with $\mathrm{HBr}$. Glycine and glutamic acid were also detected after hydrolysis of the BSP conjugates. However, these amino acids were found in hydrolysates of control bile processed in the same fashion as BSP bile. Therefore, these authors regarded glycine and glutamic

* This work was supported by research grants from the United States Public Health Service ( $\mathrm{H}-3439)$ and the American Heart Association. The authors are indebted to Mrs. Ruthie Rose for valuable technical assistance.

$\dagger$ Established Investigator of the American Heart Association. acid as possible contaminants of the BSP metabolites.

In the present report, evidence will be presented that BSP is conjugated with glutathione in the rat. Furthermore, it will be demonstrated that the linkage of glutathione to BSP occurs through the sulfhydryl group of cysteine.

\section{MATERIALS AND METHODS}

Four to $5 \mathrm{mg}$ of $\mathrm{S}^{35}$-labeled reduced glutathione ${ }^{1}$ which contained 20 to $30 \mu \mathrm{c}$ of radioactive sulfur was injected intraperitoneally into 7 rats. Two rats received approximately $5 \mathrm{mg}$ of $\mathrm{S}^{35}$-labeled L-cystine ${ }^{1}$ containing $25 \mu \mathrm{c}$ of radioactivity. Ten $\mu \mathrm{c}$ of inorganic $\mathrm{S}^{35} \mathrm{O}_{4}$ in normal saline was administered to an additional 2 rats. Two to 4 hours later, polyethylene tubing was inserted into the common bile duct and a control bile sample was collected for 45 minutes. BSP in amounts of 4 to $5 \mathrm{mg}$ per $100 \mathrm{~g}$ body weight was then injected intravenously and additional bile was collected over the ensuing 45 minutes. In four experiments, $\mathrm{S}^{35}$-labeled $\mathrm{BSP}^{2}$ was given intravenously and bile was collected for 3 hours after the common bile duct was intubated.

Descending chromatograms of bile were made on Whatman no. 1 filter paper strips. The distribution of radioactivity and of $\mathrm{BSP}$ on the chromatograms was then determined. The chromatographic techniques and the methods of quantitating radioactivity and BSP color on chromatograms have been described in detail in a previous publication (2). Briefly, two adjacent strips 1 to $1.5 \mathrm{~cm}$ wide were cut longitudinally from the chromatograms. After sectioning at $1 \mathrm{~cm}$ intervals, radioactivity was measured on one strip by placing each segment of paper in a counting bottle containing a phosphor and counting in a liquid scintillation counter. The distribution of BSP on the adjacent strip was determined by eluting the BSP contained in each segment of paper into $0.1 \mathrm{~N}$ potassium hydroxide and measuring the optical density of the eluate in a Beckman DU spectrophotometer set at $575 \mathrm{~m} \mu$. Where the ratio of counts to BSP color in a single BSP compound was determined before and after passing the compound through an ion exchange

1 Schwarz Laboratories, Inc., Mount Vernon, N. Y.

2 Volk Radiochemical Co., Chicago, Ill. 
column or acid hydrolysis, duplicate chromatograms of the BSP compound were developed. Total radioactivity contained in the BSP spot on one chromatogram and BSP color contained on the duplicate were determined.

To prepare BSP compounds for chemical analysis and amino acid chromatography, BSP bile was pooled from several rats. The BSP compounds were separated by descending chromatography as previously described (2). The BSP-containing bands were located on the paper by exposure to ammonia vapors and eluted into water. The eluate was passed through the Dowex $50-\times 8200$ to 400 mesh ion exchange column to remove any free amino acids or peptides that migrate with the same $R_{\mathfrak{f}}$ as the BSP compounds. The resulting solutions were concentrated under a stream of nitrogen in a $60^{\circ} \mathrm{C}$ water bath.

Conjugation of the lactone ring in the BSP compounds with amino acids to form a peptide bond was tested for by examining the capacity of the compounds to form hydroxamic acids. One $\mathrm{ml}$ of the concentrated BSP solutions was evaporated to dryness in a water bath at $60^{\circ} \mathrm{C}$ and the procedure outlined by Bauer and Hirsch (6) was followed. BSP standards were run simultaneously with the BSP compounds separated from bile.

The reactions with hydroxylamine and nitroprusside on paper as described by Stadtman (7) were used to determine the presence of a thioester linkage in the major $\mathrm{BSP}$ conjugate. The reactions of $\mathrm{S}$-acetyl glutathione, a known thioester, and free BSP were also examined.
The presence of a thioether bond in the major BSP conjugate was tested for by the iodometric method of Stekol (8). An excess of iodine was added to the solution and the quantity of iodine consumed was determined by back titration with standard thiosulfate solution. The molarity of the iodine and thiosulfate solutions used was $0.0005 \mathrm{M}$ since very small quantities of the BSP conjugate were available for analysis. Even at these low concentrations, recovery of mercaptoethanol, a known $\mathrm{SH}$ compound, was satisfactory. Thus, when $1 \mathrm{ml}$ of a $5 \times$ $10^{-4} \mathrm{M}$ solution of mercaptoethanol was analyzed directly for its $\mathrm{SH}$ content, the recovery was 108 per cent (Table VI).

The sodium azide-iodine reaction was performed as a spot test as outlined by Feigl (9). One drop of the test solution was mixed with one drop of sodium azide-iodine solution. The time at which bubbles were first detected and the character of the bubbles were noted.

To identify the amino acid composition of the BSP compounds, the conjugates were hydrolyzed in $5.9 \mathrm{~N}$ $\mathrm{HCl}$ in sealed glass tubes for 16 to 18 hours at $110^{\circ} \mathrm{C}$. Aliquots were pipetted onto a watch glass and brought to dryness under a stream of hot air. After redissolving in water and redrying to get rid of traces of $\mathrm{HCl}$, the material was subjected to two-dimensional amino acid chromatography on filter paper $(10,11)$. Standard amino acids as well as hydrolyzed samples of glutathione were chromatographed simultaneously.

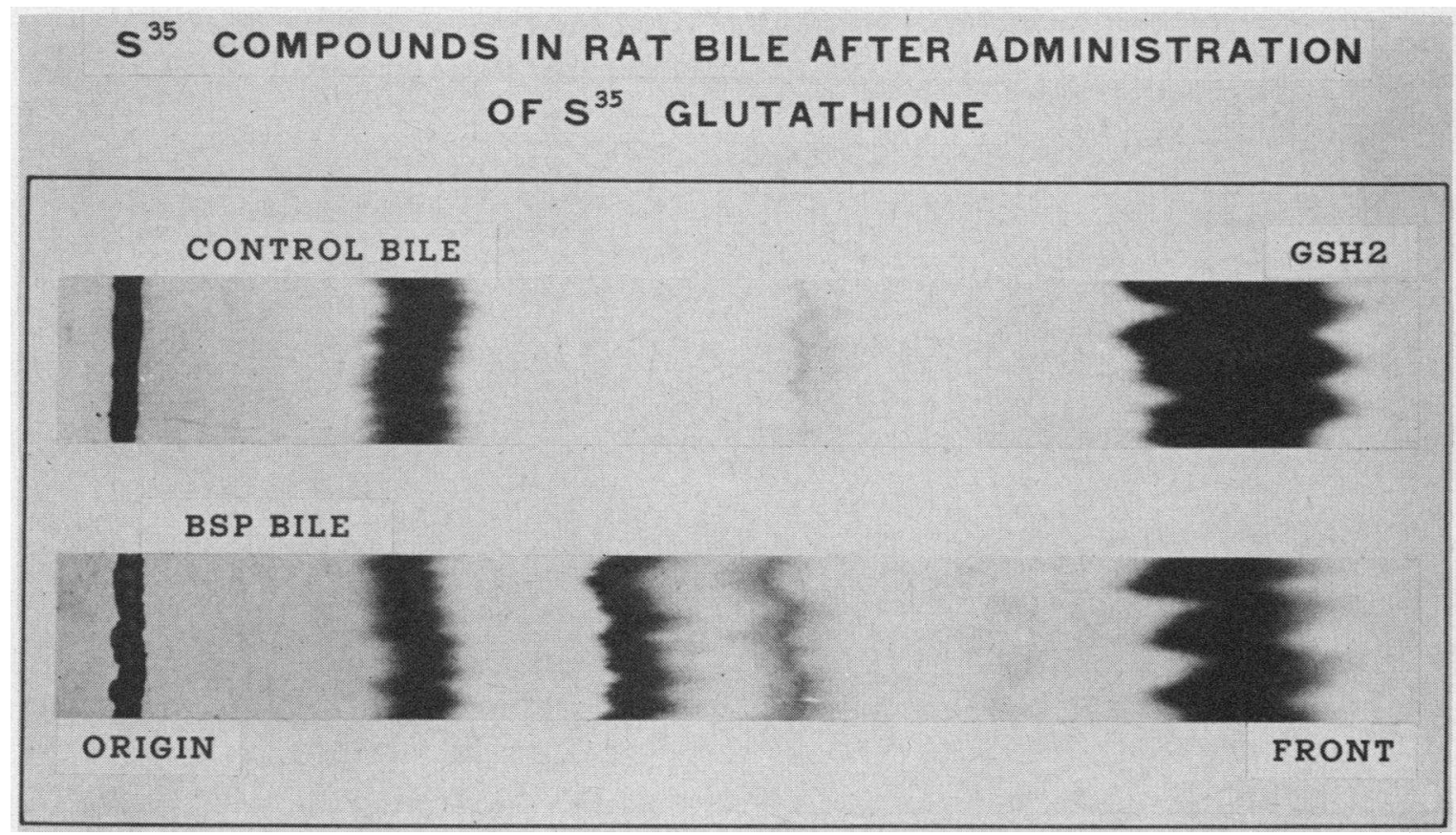

Fig. 1. Radioautographs of chromatograms of control bile and BSP bile in Rat GSH 2 . Control bile was obtained after $\mathrm{S}^{35}$-labeled glutathione was administered intraperitoneally. BSP was then injected intravenously and a BSP bile sample collected. Equal volumes of control and BSP bile were chromatographed on Whatman no. 1 filter paper strips in a descending system consisting of glacial acetic acid: water: $n$-propyl alcohol $(1: 5: 10$, vol/vol). The papers were dried and radioautographs developed. 
RESULTS

1. Incorporation of radioactivity from $S^{35}$-labeled glutathione and $S^{35}$-labeled cystine into BSP conjugates

Radioactivity was associated with the BSP conjugates identified on chromatograms of bile collected from rats receiving $\mathrm{S}^{35}$-labeled glutathione and $\mathrm{S}^{35}$-labeled cystine. A representative radioautograph of such chromatograms from a rat receiving radioactive glutathione is demonstrated in Figure 1. Radioactive material was present in control bile obtained before BSP was administered. Similar radioactive bands were also detected in bile collected after BSP was injected. In addition, however, a very dense band, not detected in control bile, is seen in BSP bile. Other bands are seen in BSP bile, but it is difficult to be sure on the basis of such radioautographs whether they represent a qualitative or quantitative difference between control and BSP bile. since faint bands in similar location are seen in control bile.

The distribution of $\mathrm{BSP}$ and of radioactivity on the chromatogram from which the radioautograph in Figure 1 was made can be seen in Figure 2. Values for optical density due to BSP are plotted on the upper half of the figure. Three BSP peaks are evident. The first, which has its

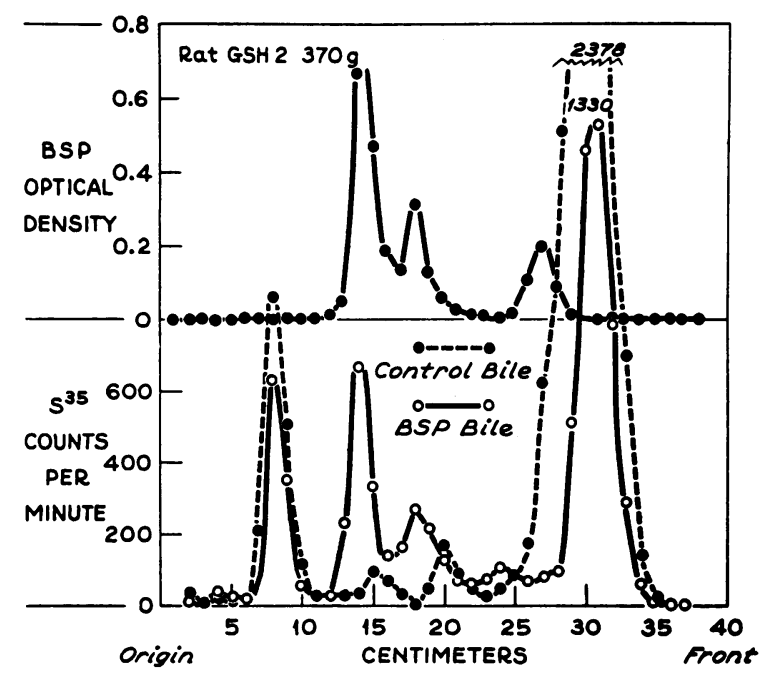

Fig. 2. The distribution of radioactivity and of BSP ON THE CHROMATOGRAMS OF RAT GSH 2. The radioautographs of these chromatograms are shown in Figure 1 . See text for description. peak at $14 \mathrm{~cm}$ from the origin of the chromatograph, corresponds to $\mathrm{BSP} \mathrm{A}$, the major $\mathrm{BSP}$ conjugate in rat bile. The second has its peak $18 \mathrm{~cm}$ from the origin and corresponds to BSP B, another $\mathrm{BSP}$ conjugate. The third peak is at $27 \mathrm{~cm}$ and is composed of BSP D, which has been shown to be free BSP. The $\mathrm{S}^{35}$ in control and BSP biles is plotted on the lower half of Figure 2 . It is evident that peaks of radioactivity which conform in shape and position with the BSP conjugates, BSP A and BSP B, are present only in $\mathrm{BSP}$ bile. The BSP conjugates in all of the animals receiving $S^{35}$-labeled glutathione and $S^{35}$ labeled cystine were labeled. By contrast, the free $\mathrm{BSP}$ excreted in bile did not contain radioactivity.

The ratio of counts per minute per unit optical density in BSP A was determined before and af-

TABLE I

Relationship of $S^{35}$ counts to BSP optical density in BSP $A$ obtained from rats receiving $S^{35}$-labeled glutathione

\begin{tabular}{|c|c|c|}
\hline Rat & $\begin{array}{l}\text { Not through } \\
\text { Dowex-50 } \times\end{array}$ & $\begin{array}{c}\text { Through } \\
\text { Dowex-50 } \times\end{array}$ \\
\hline no. & \multicolumn{2}{|c|}{$c p m / U$ optical density } \\
\hline $\begin{array}{l}\text { GSH } 4 \\
\text { GSH } 7 \\
\text { GSH } 8\end{array}$ & $\begin{array}{r}1,724 \\
1,328 \\
973\end{array}$ & $\begin{array}{r}1,798 \\
1,303 \\
947\end{array}$ \\
\hline
\end{tabular}

ter passing BSP A through a Dowex-50 $\times 200$ to 400 mesh ion exchange column. BSP A readily passes through the column and is not altered by the procedure, whereas free amino acids and small peptides are bound to the column. It can be seen (Table I) that the quantity of radioactivity associated with the $\mathrm{BSP}$ conjugate remains the same after passing BSP A through the Dowex column, indicating that the $S^{35}$ is an intimate part of the BSP conjugate.

2. Site of $S^{35}$ incorporation into the BSP molecule in BSP conjugates

Several possible alternatives by which $S^{35}$ from labeled glutathione and cystine could become a part of the BSP conjugates were examined.

a) Exchange of sulfur in the sulfonic acid groups. This exchange should occur only in the BSP conjugates, since the $\mathrm{S}^{35}$ label of glutathione was introduced only into the BSP conjugates and 
TABLE II

Comparison of $S^{35}$ counts to optical density in BSP $A$ and $B S P D$ after administration of $B S^{35} P$

\begin{tabular}{ccc}
\hline \hline Experiment & BSP A & BSP D \\
\hline no. & \multicolumn{2}{c}{$c$ pm/U optical density } \\
1 & 49,400 & 48,600 \\
2 & 69,300 & 72,100 \\
3 & 47,500 & 50,100 \\
4 & 51,700 & 51,400 \\
\hline
\end{tabular}

not into free BSP. Thus, when BSP labeled with $S^{35}$ in the sulfonic acid group is administered, sulfur exchange in the conjugates should lead to a lowering of their specific activity as compared with free BSP. The ratio of counts per minute per unit optical density due to BSP in BSP A and BSP D was determined in four experiments (Table II). The specific activities of the major $\mathrm{BSP}$ conjugate and free BSP did not differ significantly. Additional evidence against sulfur exchange is provided by the inorganic $\mathrm{S}^{35} \mathrm{O}_{4}$ experiments, in which no evidence was found for incorporation of radioactivity into the BSP compounds (Figure 3).

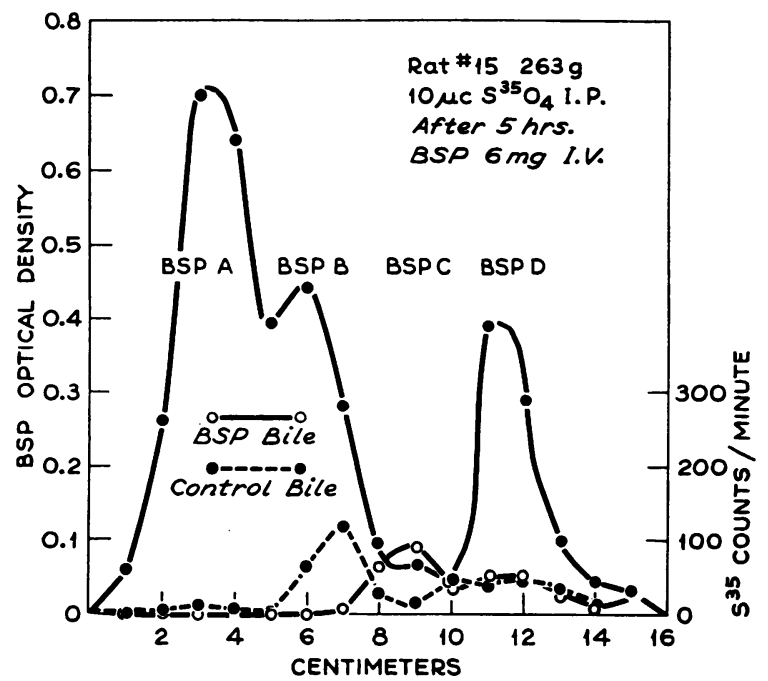

Fig. 3. THE Distribution OF RADIOACTIVITY AND OF BSP ON THE CHROMATOGRAMS OF A RAT RECEIVING INORGANIC $\mathrm{S}^{35} \mathrm{O}_{4}$. Only that segment of the chromatograms containing the BSP bands is shown. The values for BSP optical density are indicated by the solid line with solid circles. The $\mathrm{S}^{35}$ counts per minute contained in BSP and control bile are shown by the solid line with open circles and the dashed line with solid circles, respectively. No incorporation of radioactivity into the BSP compounds is demonstrated. b) Formation of an ethereal sulfate. The ratio of counts per minute per unit optical density in BSP A obtained from rats given $\mathrm{S}^{35}$-labeled glutathione was determined before and after heating a solution of $\mathrm{BSP} \mathrm{A}$ at $100^{\circ} \mathrm{C}$ for 30 minutes in $1 \mathrm{~N} \mathrm{HCl}$ (Table III). Ethereal sulfates are known to be hydrolyzed under these conditions (12). No decrease in specific activity of the BSP conjugate was detected after hydrolysis in weak acid.

As a further test for the presence of an ethereal sulfate in the BSP compounds, radioactive inorganic sulfate was administered to two rats to see whether the radioactivity would appear in the BSP conjugates. This was carried out, since Isselbacher and McCarthy demonstrated radioactive label in the ethereal sulfate of bilirubin collected in bile when inorganic $\mathrm{S}^{35} \mathrm{O}_{4}$ was administered intraperitoneally to rats (13). In the two rats given inorganic $\mathrm{S}^{35} \mathrm{O}_{4}$ and then $\mathrm{BSP}$, no ra-

TABLE III

Effect of heating $B S P$ A from rat receiving $S^{35}$-labeled glutathione, at $100^{\circ} \mathrm{C}$ for 30 minutes in $1 \mathrm{~N} \mathrm{HCl}$

Counts per minute/U optical density

$\begin{array}{lll}\text { Before heating } & 300 & 298 \\ \text { After heating } & 296 & 288\end{array}$

dioactivity appeared in the BSP compounds recovered in bile. The distribution of BSP and of radioactivity on the chromatograms of one such animal is shown in Figure 3.

c) Conjugation with the lactone ring of BSP. Two types of linkage with the lactone ring of BSP might exist, namely peptide and thioester. The hydroxylamine reaction was used to test for the presence of a peptide bond in the BSP conjugates. If the lactone ring were engaged in peptide linkage, the BSP conjugates would not form hydroxamic acids. It was observed that free BSP (BSP D), BSP A and BSP C, obtained from bile pooled from several rats, all formed hydroxamic acids (Table IV). The ratio of found optical density to that in free BSP was 1.20 for BSP A and 1.18 for BSP C. Such deviations from unity are within the range of experimental error of the method. Although these findings ruled out the participation of the lactone ring with amino acids in peptide linkage, they did not ex- 
TABLE IV

Reaction of BSP compounds with hydroxylamine

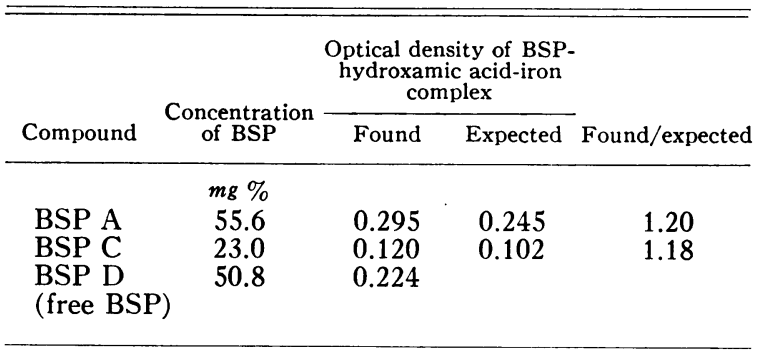

clude a thioester bond, for thioesters have been shown to react with hydroxylamine to form hydroxamic acids (7). Therefore, the reaction of BSP A with hydroxylamine on paper (7) was carried out. A free sulfhydryl group should be identified after reaction of a thioester with hydroxylamine. Free BSP, S-acetyl glutathione, a mixture of these two, and BSP A formed hydroxamic acids after treatment with hydroxylamine, as evidenced by a positive reaction with ferric chloride reagent (Table V). Whereas none of the compounds exhibited a positive reaction for free sulfhydryl groups before the hydroxylamine reaction, a free sulfhydryl group was now demonstrable on the papers containing S-acetyl glutathione. When the nitroprusside reagent was added to the mixture of S-acetyl glutathione and BSP after treatment with hydroxylamine, a purple color due to the BSP appeared first and then rapidly faded. A red color attributed to the presence of a free sulfhydryl group was then clearly demonstrable before it also faded. No red color was discernible in the BSP A spot. A thioester linkage in BSP A thus seemed

TABLE $V$

Reactions for presence of a thioester bond

\begin{tabular}{|c|c|c|c|}
\hline \multirow[b]{2}{*}{ Compound } & \multirow[b]{2}{*}{$\begin{array}{l}\text { Formation of } \\
\text { hydroxamic } \\
\text { acid }\end{array}$} & \multicolumn{2}{|c|}{ Free sulfhydryl group } \\
\hline & & $\begin{array}{l}\text { Before } \\
\text { hydroxyl- } \\
\text { amine }\end{array}$ & $\begin{array}{c}\text { After } \\
\text { hydroxyl- } \\
\text { amine }\end{array}$ \\
\hline $50 \mu \mathrm{l} 100 \mathrm{mg} \%$ BSP & + & 0 & 0 \\
\hline $\begin{array}{l}50 \mu \mathrm{l} 50 \mathrm{mg} \% \mathrm{~S} \text {-acetyl } \\
\text { glutathione }\end{array}$ & + & 0 & + \\
\hline $\begin{array}{c}50 \mu \mathrm{l} 100 \mathrm{mg} \% \mathrm{BSP} \\
+50 \mu \mathrm{l} 50 \mathrm{mg} \% \\
\text { S-acetyl glutathione }\end{array}$ & + & 0 & + \\
\hline $\begin{array}{l}\text { BSP A } 550 \mathrm{mg} \% \\
20 \mu \mathrm{l} \\
100 \mu \mathrm{l}\end{array}$ & + & $\begin{array}{l}0 \\
0\end{array}$ & $\begin{array}{l}0 \\
0\end{array}$ \\
\hline
\end{tabular}

unlikely. It can be concluded, therefore, that no opening of the lactone ring accompanies conjugation of BSP with amino acids.

d) Thioether linkage with BSP. No evidence was detected of a free sulfhydryl group in unhydrolyzed BSP A. However, after alkaline hydrolysis of the conjugate, approximately one sulfhydryl group was titrated iodometrically for each mole of BSP in two separate pools of BSP A (Table VI). Free BSP did not react with iodine.

These findings, which indicate the presence of bound sulfur in the major BSP conjugates, were supported by results obtained with the qualitative sodium azide-iodine reaction (9). A positive re-

TABLE VI

Titration of BSP compounds with iodine and thiosulfate solutions

\begin{tabular}{|c|c|c|c|c|}
\hline \multirow[b]{2}{*}{ Compound } & \multirow{2}{*}{$\begin{array}{l}\text { Molarity of } \\
\text { sample }\end{array}$} & \multirow{2}{*}{$\begin{array}{l}\text { Volume of } \\
\text { sample } \\
\text { analyzed }\end{array}$} & \multicolumn{2}{|c|}{$\begin{array}{l}0.0005 \mathrm{~N} \text { iodine } \\
\text { consumption }\end{array}$} \\
\hline & & & Found & Expected \\
\hline & & $m l$ & \multicolumn{2}{|c|}{$m l$} \\
\hline Free BSP & $6.0 \times 10^{-4}$ & 1.0 & $0^{*}$ & 0 \\
\hline BSP A, Pool 1 & $6.4 \times 10^{-4}$ & 1.0 & $1.06^{*}$ & 1.28 \\
\hline BSP A, Pool 2 & $6.6 \times 10^{-4}$ & 1.0 & $1.10^{*}$ & 1.32 \\
\hline Mercaptoethanol & $5.0 \times 10^{-4}$ & 1.0 & $1.08 t$ & 1.00 \\
\hline
\end{tabular}

* Corresponds to milliliters iodine consumed after alkaline hydrolysis minus milliliters consumed by blank.

$\dagger$ Milliliters iodine used in titration of unhydrolyzed sample.

action is indicated by the evolution of bubbles of nitrogen. When cysteine was mixed with sodium azide-iodine, bubbles were detected as indicated in Table VII. BSP A also gave a positive reaction. However, when compared with cysteine, the onset of visible reaction was delayed and the bubbles evolved were very fine. Cystine, a compound with bound sulfur, reacted even more slowly than did BSP A. Free BSP did not give a positive reaction.

\section{Amino acids detected after hydrolysis of BSP compounds}

Glycine, glutamic acid and alanine were identified in hydrolysates of BSP A, BSP B and BSP C. No amino acids were associated with BSP D, the compound which corresponds to free BSP. The ninhydrin spots conforming to glycine and glutamic acid were usually of equal size and color intensity. Occasionally, in hydrolysates of BSP B 
TABLE: VII

Results of the sodium azide-iodine reaction*

\begin{tabular}{ccccc}
\hline \hline & \multicolumn{4}{c}{ Time in seconds at which bubbles } \\
first developed \\
\cline { 2 - 5 } $\begin{array}{c}\text { Molarity of } \\
\text { solution }\end{array}$ & $\begin{array}{c}\text { Cysteine } \\
\text { (R-SH) }\end{array}$ & $\begin{array}{c}\text { BSP A } \\
(\text { R-S-R })\end{array}$ & $\begin{array}{c}\text { Cystine } \\
\text { (R-S-S-R })\end{array}$ & BSP \\
\hline 0.0004 & 12 & $50-60$ & 90 & None \\
0.0003 & 30 & 90 & $>120$ & None
\end{tabular}

* One drop of the test solution was mixed with 1 drop of sodium azide-iodine reagent. There were approximately 32 drops per $\mathrm{ml}$.

and BSP C, the glycine spot was more prominent than the glutamic acid spot. Alanine was always less prominent than glycine and glutamic acid. On some chromatograms, alanine was not detected until the chromatogram was "loaded" with the hydrolysate of the BSP compound.

Oxidation of each hydrolysate was also carried out with hydrogen peroxide and ammonium molybdate on a second chromatogram, as outlined by Dent (10), to facilitate the identification of cysteine. Cysteine and glutamic acid migrate very close to each other and usually are superimposed in the solvent systems used. However, after oxi- dation, cysteine is converted to cysteic acid, a compound which is easily separated chromatographically from glutamic acid, and thus can be definitely identified. Despite use of this method, cysteine was not detected, even when $30 \mu \mathrm{g}$ of BSP was placed on the chromatograms. Assuming that BSP is conjugated with one molecule of glutathione, approximately 10 to $12 \mu \mathrm{g}$ of hydrolyzed glutathione was put on paper. By contrast, cysteine (as cysteic acid) was regularly identified in hydrolysates of glutathione alone and in mixtures of equimolar concentrations of glutathione and BSP when as little as $1.84 \mu \mathrm{g}$ of hydrolyzed glutathione was put on paper. The cysteic acid spot observed with ninhydrin was less intense than were the glycine and glutamic acid spots.

Since alanine but not cysteine was identified in hydrolysates of BSP conjugates, the possibility that the sulfur of cysteine remained attached to the $\mathrm{BSP}$ molecule after $\mathrm{HCl}$ hydrolysis was examined. BSP A isolated from a rat given $\mathrm{S}^{35}$ labeled L-cystine was hydrolyzed in $5.9 \mathrm{~N} \mathrm{HCl}$ at 15 pounds pressure for 3 hours. A chromatogram of the hydrolyzed material was developed, and BSP bands were identified. Radioactivity on

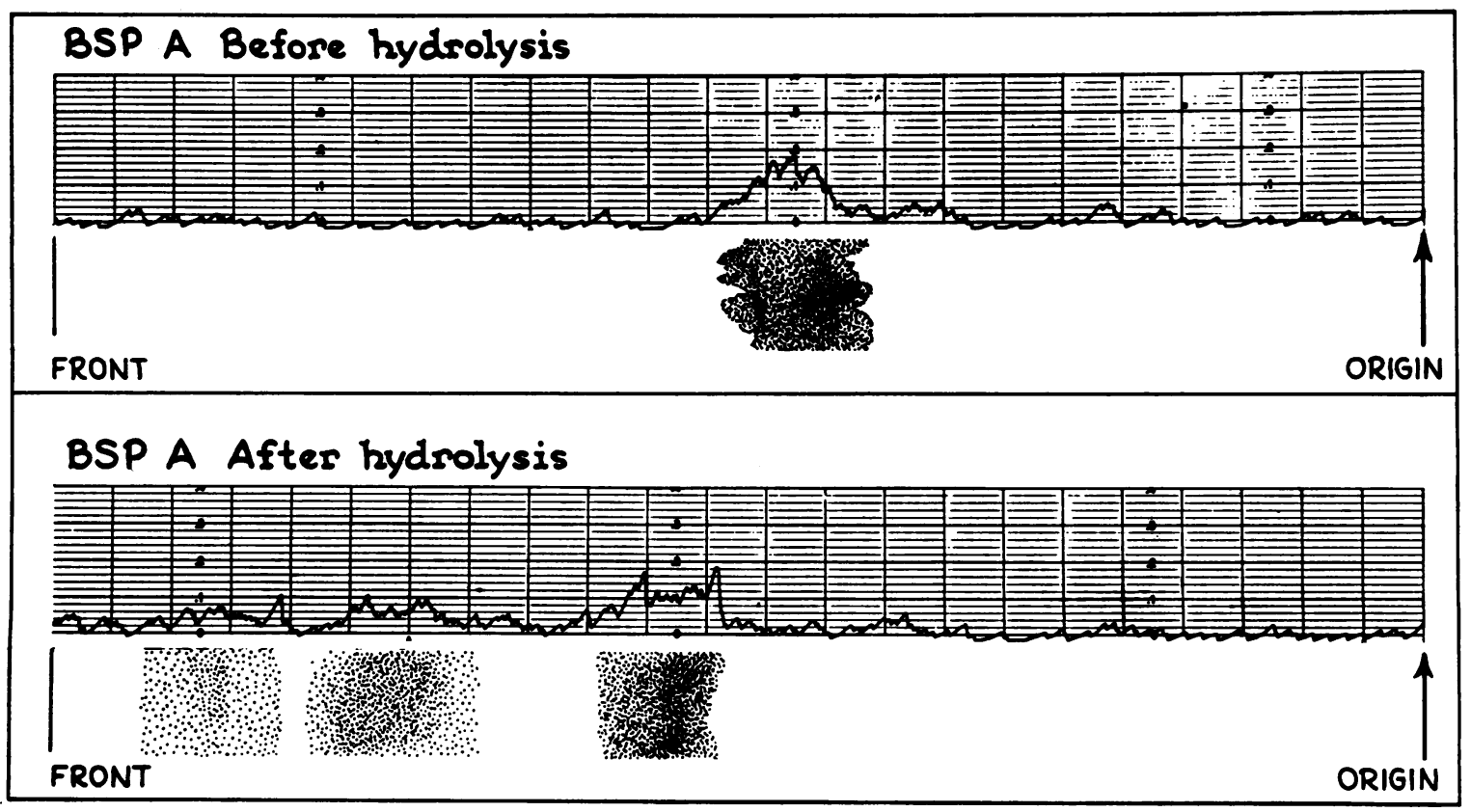

Fig. 4. Relationship of Radioactivity to BSP Bands before and After acid hydrolysis of BSP A. BSP A was isolated from the bile of a rat that had received $\mathrm{S}^{35}$-labeled cystine. BSP A was partially hydrolyzed in $5.9 \mathrm{~N} \mathrm{HCl}$ by heating at $100^{\circ} \mathrm{C}$ for 3 hours at 15 pounds pressure. Drawings of chromatograms of BSP A before and after hydrolysis are shown. Radioactivity was associated with the hydrolytic BSP products. 
the chromatograms was then located by a chromatogram scanner. ${ }^{3}$ Three BSP-containing bands with $R_{f ' s}$ of $0.56,0.77$ and 0.87 , respectively, were seen after hydrolysis. The $\mathrm{R}_{\mathrm{f}}$ of unhydrolyzed BSP A was 0.48 and that of free BSP, 0.76. When free BSP is subjected to acid hydrolysis and then chromatographed, at least two compounds are identified. One travels with the same $R_{f}$ as does free BSP, the other moves more quickly (2). Therefore, the BSP bands moving with $\mathrm{R}_{\mathbf{f}}$ 's of 0.77 and 0.87 in the hydrolyzed sample of BSP A no doubt corresponded to these BSP moieties. Radioactivity was associated with all three BSP compounds (Figure 4), indicating that the $\mathrm{S}^{35}$ of cysteine remains attached to the BSP molecule after hydrolysis.

\section{DISCUSSION}

The present studies indicate that cysteine as well as glycine and glutamic acid is present in the BSP conjugates. Thus, radioactivity conforming in shape and position with the BSP conjugates, but not free BSP, was regularly identified on chromatograms of bile collected from animals that had received $\mathrm{S}^{35}$-labeled reduced glutathione and $\mathrm{S}^{35}$-labeled L-cystine. The radioactivity was intimately associated with the BSP compound since it could not be removed by passing BSP A through a Dowex-50× 200 to 400 mesh ion exchange column. Incorporation of the radioactive sulfur into BSP conjugates need not be attributed to cysteine conjugation, however. Radioactivity might appear in the BSP compounds by $\mathrm{S}^{35}$ exchange with the sulfonic acid groups or by formation of an ethereal sulfate with the hydroxyl groups of BSP. Both of these possibilities seem to have been excluded. Since radioactivity appeared only in the BSP conjugates when $\mathrm{S}^{35}$-labeled glutathione and $\mathrm{S}^{35}$-labeled L-cystine were administered, sulfur exchange would have occurred in the conjugates and not in free BSP. It was reasoned, therefore, that sulfur exchange should be indicated by a lowering of the specific activity of the BSP conjugates and not of free BSP when $S^{35}$-labeled BSP was administered. The specific activities of BSP A and BSP D (free BSP) eluted from paper chromatograms did not differ significantly. In

\footnotetext{
3 Model RSC-5A chromatogram scanner manufactured by Atomic Accessories, Inc.
}

addition, no radioactivity appeared in the BSP conjugates in the rats given inorganic $\mathrm{S}^{35} \mathrm{O}_{4}$. Sulfur exchange was therefore ruled out. Formation of an ethereal sulfate of BSP appears to be excluded by the observation that the ratio of $S^{35}$ counts per minute per unit optical density of BSP in BSP A was not altered under conditions in which hydrolytic cleavage of an ethereal sulfate would be expected. This finding was supported by the less specific inorganic $\mathrm{S}^{35} \mathrm{O}_{4}$ experiments, in which no evidence was found of incorporation of radioactivity into the $\mathrm{BSP}$ conjugates.

It seemed likely, therefore, that the association of radioactivity with the BSP conjugates in animals receiving $\mathrm{S}^{35}$-labeled glutathione and L-cystine was due to incorporation of cysteine in the BSP conjugates. Chromatograms of BSP conjugates hydrolyzed with $5.9 \mathrm{~N} \mathrm{HCl}$ failed to reveal this amino acid, however. In part, this could be explained by destruction of cysteine which is known to occur during hydrolysis with strong $\mathrm{HCl}$ (14). Nevertheless, such an explanation could not account for the inability to find cysteine when hydrolysates containing up to $30 \mu \mathrm{g}$ of BSP were placed on the chromatograms. Such chromatograms would contain approximately $4.3 \mu \mathrm{g}$ of cysteine, assuming that one mole of cysteine is conjugated with one mole of BSP. Even the much smaller quantity of cysteine contained in 1.8 $\mu \mathrm{g}$ of reduced glutathione, approximately $0.7 \mu \mathrm{g}$, was readily detected chromatographically when glutathione either alone or containing an equimolar amount of free BSP was hydrolyzed with $5.9 \times \mathrm{HCl}$. The presence of alanine on the amino acid chromatograms suggested another possibility. namely, that the sulfhydryl group of cysteine was split off during acid hydrolysis. Indeed, this was confirmed by finding radioactivity associated with the hydrolytic products liberated during hydrolysis of BSP A obtained from a rat that had received $S^{35}$-labeled L-cystine. From the size and color intesity of the alanine spot on amino acid chromatograms, desulfuration of cysteine with liberation of alanine seemed to be more significant quantitatively than was destruction of cysteine to non-ninhydrin-reacting products in explaining the inability to detect cysteine chromatographically.

In the present studies, evidence of a thioether bond between the sulfhydryl group of cysteine and BSP was adduced from the observation that ap- 
proximately one sulfhydryl group was titrated for one mole of BSP after alkaline hydrolysis of $\mathrm{BSP} A$, the major conjugate in the rat, whereas no titrable sulfhydryl group was present prior to hydrolysis. Similar results would have been obtained if the sulfhydryl group of cysteine was conjugated with the lactone ring of BSP in thioester linkage. The absence of a free sulfhydryl group after reaction of $\mathrm{BSP} \mathrm{A}$ with hydroxylamine excluded a thioester bond, however. Absence of a free sulfhydryl group in the intact BSP conjugate also implies that cysteine is not bound in peptide linkage. The results obtained in the reaction between the BSP conjugates and hydroxylamine afford additional evidence for this. Free BSP contains a lactone ring which is capable of forming a hydroxamic acid. If the lactone ring were engaged in peptide bond formation, hydroxamic acid formation would be unlikely. The observation that the conjugates BSP A and BSP C, like free BSP, formed hydroxamic acids ruled out such a linkage. Since cysteine can be easily identified in hydrolysates of glutathione, a compound in which this amino acid exists in peptide linkage, it seems likely that difficulty in identifying cysteine in hydrolysates of BSP conjugates is related to the existence of the thioether bond. During hydrolysis of the $\mathrm{BSP}$ thioether linkage with strong $\mathrm{HCl}$, the sulfhydryl group tends to remain attached to the BSP molecule.

In confirmation of earlier studies (2), glycine and glutamic acid were identified in hydrolysates of BSP conjugates. It was previously pointed out that these amino acids are found occasionally when control bile is chromatographed and the areas with the same $R_{\mathbf{r}}$ s as the BSP compounds are eluted, hydrolyzed and then chromatographed for amino acids. The compounds in control bile that yield these amino acids on acid hydrolysis can be removed, however, by passing them through a Dowex-50x ion exchange column (2). BSP conjugates are not altered by this procedure. Therefore, eluates containing BSP compounds are regularly passed through such a column before hydrolysis and amino acid chromatography in this laboratory. Glycine and glutamic acid were regularly identified in all of the BSP conjugates. The amounts of glycine and glutamic acid liberated by hydrolysis were not quantitated chemically. However, approximately one mole of glycine and of glutamic acid were usually present for each mole of BSP, as estimated by paper chromatography. Alanine, which we consider to be cysteine minus its $\mathrm{SH}$ group, was also present in chromatograms of the BSP conjugates. Thus glycine, glutamic acid and cysteine were bound to $\mathrm{BSP}$ to form the BSP conjugates appearing in rat bile. These three amino acids compose the tripeptide glutathione. It may be concluded, therefore, that $\mathrm{BSP}$ is conjugated in the liver of the rat with glutathione, conjugation occurring through the sulfhydryl group of cysteine. We would also interpret our earlier finding of the presence of glycine, glutamic acid and alanine in hydrolysates of human BSP conjugates (2) as indicating that BSP is conjugated with glutathione in man. These conclusions are in essential agreement with the findings of Javitt, Grodsky and their respective associates. Thus, Javitt, Wheeler, Baker and Ramos, in a preliminary report, suggested that $\mathrm{BSP}$ is excreted as a glutathione conjugate in the $\operatorname{dog}$ (5). Grodsky, Carbone and Fanska "concluded that BSP is excreted at least in part as a mercaptide with cysteine or the peptide glutathione," in man (4). These latter authors are not certain about the presence of glutathione, however, since they feel that glycine and glutamic acid are possible contaminants of the BSP metabolites.

At least four distinct BSP bands can be separated by paper chromatography of rat bile (2). One band, BSP D, corresponds to free BSP. The other three, BSP A, BSP B and BSP C, are amino acid conjugates, with $\mathrm{BSP} A$ the major one. Our findings indicate that each of these latter bands contains BSP and glutathione. This implies that they are isomers with mobility in the solvent system differing with site of conjugation. We have no direct evidence for or against conjugation of BSP with 2 moles of glutathione, although visual analysis of the quantity of amino acids on paper chromatograms suggests that only 1 mole of glycine is present for each mole of BSP. The observation that BSP B and BSP C may yield more glycine than glutamic acid on hydrolysis suggests that these BSP bands may also contain breakdown products of BSP-glutathione such as BSP-cysteinyl glycine and BSP-cysteine. Quantitatively, however, BSP-glutathione is the major conjugate found in rat bile.

Our demonstration that glutathione is conju- 
gated in thioether linkage with BSP may be considered as additional evidence for the view that glutathione is involved in the formation of mercapturic acids (15). The glutathione thioether would then be split to a cysteine thioether by the action of glutathionase (16). In this regard, it is of interest that BSP has been found to be a potent inhibitor of glutathionase (17), an observation which is consistent with our finding that $\mathrm{BSP}$-glutathione is the major conjugate in rat bile.

The present studies also provide additional information about the structure of the BSP molecule appearing in the BSP conjugates. The sulfonic acid groups do not appear to be removed or engaged in sulfur exchange. The hydroxyl groups, at least in the major BSP compound, BSP A, are not conjugated with sulfate and earlier studies $(1,2)$ excluded glucuronide formation. The lactone ring remains intact. Sites available for glutathione conjugation include, therefore, the positions occupied by the four bromine atoms, and the free positions on the two phenolic rings. Krebs and Brauer found that the ratio of bromine to sulfur in Compound III of the rat (probably identical with BSP A) was the same as that in free BSP (1), suggesting that glutathione is conjugated at one of the free positions on the phenolic rings in BSP A. The determination of bromine to sulfur ratios will be of importance in elucidating the site of conjugation in the other BSP compounds.

\section{SUMMARY}

The three ninhydrin-positive sulfobromophthalein sodium (BSP) compounds appearing in rat bile have been shown to consist of BSP conjugated with the amino acids cysteine, glycine and glutamic acid. These amino acids are the constituents of glutathione. Therefore, it is concluded that most of the BSP excreted in rat bile is BSPglutathione. BSP A, the major BSP compound in rat bile, appears to be $\mathrm{BSP}$-glutathione. $\mathrm{BSP}$ $\mathrm{B}$ and BSP C may consist of isomers of BSPglutathione plus breakdown products of this compound such as BSP-cysteinyl glycine and BSPcysteine. Conjugation was shown to occur through the sulfhydryl group of cysteine with the formation of a thioether linkage.

\section{REFERENCES}

1. Krebs, J. S., and Brauer, R. W. Metabolism of sulfobromophthalein sodium (BSP) in the rat. Amer. J. Physiol. 1958, 194, 37.

2. Combes, B. The biliary excretion of sulfobromophthalein sodium (BSP) in the rat as a conjugate of glycine and glutamic acid. J. clin. Invest. 1959, 38, 1426.

3. Meltzer, J. I., Wheeler, H. O., and Cranston, W. I. Metabolism of sulfobromophthalein sodium (BSP) in dog and man. Proc. Soc. exp. Biol. (N. Y.) 1959, 100, 174.

4. Grodsky, G. M., Carbone, J. V., and Fanska, R. Identification of metabolites of sulfobromophthalein. J. clin. Invest. 1959, 38, 1981.

5. Javitt, N. B., Wheeler, H. O., Baker, K. J., and Ramos, O. Intrahepatic conjugation of bromsulphalein and glutathione (abstract). J. clin. Invest. 1959, 38, 1015.

6. Bauer, F. C., Jr., and Hirsch, E. F. A new method for the colorimetric determination of the total esterified fatty acids in human sera. Arch. Biochem. 1949, 20, 242.

7. Stadtman, E. R. The net enzymatic synthesis of acetyl coenzyme A. J. biol. Chem. 1952, 196, 535.

8. Stekol, J. A. The determination of $p$-bromophenylmercapturic acid in the urine of the dog. J. biol. Chem. 1936, 113, 279.

9. Feigl, F. Spot tests in Organic Analysis, 5th ed. New York, Elsevier Publishing, 1956.

10. Dent, C. E. A study of the behaviour of some sixty amino-acids and other ninhydrin-reacting substances on phenol-'collidine' filter-paper chromatograms, with notes as to the occurrence of some of them in biological fluids. Biochem. J. 1949, 43, 169.

11. Datta, S. P., Dent, C. E., and Harris, H. An apparatus for the simultaneous production of many two-dimensional paper chromatograms. Science 1950, 112, 621.

12. Folin, O. On sulphate and sulphur determinations. J. biol. Chem. 1906, 1, 131.

13. Isselbacher, K. J., and McCarthy, E. A. Studies on bilirubin sulfate and other nonglucuronide conjugates of bilirubin. J. clin. Invest. 1959, 38, 645

14. Block, R. J., and Weiss, K. W. Amino Acid Handbook. Methods and Results of Protein Analysis. Springfield, Ill., Charles C Thomas, 1956.

15. Barnes, M. M., James, S. P., and Wood, P. B. The formation of mercapturic acids. I. Formation of mercapturic acid and the levels of glutathione in tissues. Biochem. J. 1959, 71, 680.

16. Bray, H. G., Franklin, T. J., and James, S. P. The formation of mercapturic acids. 2. The possible role of glutathionase. Biochem. J. 1959, 71, 690.

17. Binkley, F., and Olson, C. K. Metabolism of glutathione. IV. Activators and inhibitors of the hydrolysis of glutathione. J. biol. Chem. 1951, $188,451$. 